\title{
Verbal mediation in reverse association: The role of temporal factors
}

RICHARD A. KULP AND JOHN A. ROBINSON

UNIVERSITY OF LOUISVILLE

\begin{abstract}
A three stage reverse mediation paradigm, A-B, $\mathrm{B}-\mathrm{C}, \mathrm{C}-\mathrm{A}$ and its control paradigm $\mathrm{A}-\mathrm{B}, \mathrm{D}-\mathrm{C}, \mathrm{C}-\mathrm{A}$, was studied at two test list anticipation intervals to determine the effects of temporal factors on reverse mediation. Forty-eight Ss learned three word lists consisting of low-frequency five letter words by the paired-associate method. The results indicated that temporal factors play a significant role in facilitating reverse mediation.
\end{abstract}

\section{Introduetion}

The effect of temporal factors on mediation in a verbal paired associate learning task has recently been investigated by Schulz \& Lovelace (1964). They used a forward association paradigm $(A-B, C-D, A-D)$ and two test list anticipation intervals, 2 and $4 \mathrm{sec}$. The results indicated that mediation was significantly facilitated by increasing the test list anticipation interval. Storms (1958) using a 2 sec. testlist anticipation interval failed to demonstrate mediation effects, however, McCormack (1961) using the same interval obtained a significant mediation effect.

The present experiment was designed to further investigate the role of temporal factors in mediation to determine whether (a) a significant mediation effect would be obtained using a reverse association paradigm and (b) increasing the anticipation interval of the test list would facilitate mediation in reverse association. Method

A three stage reverse mediation paradigm (A-B, $\mathrm{B}-\mathrm{C}, \mathrm{C}-\mathrm{A})$ at two test list anticipation intervals was investigated. The experimental or mediation (M) group and the control or non-mediation (NM) group served under a 2 sec.-short (S) or a 4 sec.-long (L) condition. All subjects (Ss) learned the first two lists (A-B, B-C or $A-B, D-C)$ at a 2:2 sec. rate, that is, stimulus word alone $2 \mathrm{sec}$. and stimulus and response words together 2 sec. During the test stage the anticipation interval was either $\mathrm{S}$ or $\mathrm{L}$ depending upon the experimental condition. The study interval remained constant in all stages and for all groups. No interpair interval was used $_{\imath}$ however, a 4 sec. intertrial interval was employed.

Twenty-four low-frequency five-letter words selected from the Thorndike-Lorge list (1944) and scaled for association values by Horton \& Kjeldergaard (1961) were assigned to four separate lists as shown in Table 1.

To control for the ease with which words or word pairs are learned and effects due to having certain words appear only in stimulus or response position, the following controls were exercised.Lists 1,2 , and 3
Table 1. Learning Materials

\begin{tabular}{|llll|}
\hline List 1 & List 2 & List 3 & List 4 \\
\hline CARIN & UMBER & MERLE & TRIPE \\
LLANO & NILUM & SWALE & ETUDE \\
TRYST & PRAWN & BEDEW & BLEAR \\
DELFT & FAGOT & KRAAL & WINCH \\
VENAL & REAVE & DRAFF & DAVIT \\
ARRAS & KRONE & NADIR & LIMBO \\
& & & \\
\hline
\end{tabular}

were designated as the experimental words. The words in the experimental lists were randomly paired to provide four different list-position combinations. The control words, list 4 , were randomly substituted for the experimental words in the list common to the first two stages. This substitution was made in the second stage of the chaining paradigm. To prevent the effects due to serial learning five randomizations of each list of pairs were used.

The lists were presented on a Stowe Model 459 B memory drum.

Two groups of male volunteers, 16 in each group, served as subjects (Ss) for the experimental groups, and two groups of 8 each served as Ss for the control groups. The only restriction on the random assignment of the Ss was that the intelligence of the Ss was matched across groups. The Ammons and Ammons Quick Test (1962) was used to obtain a general index of the S's verbal aptitude. All Ss were enlisted men assigned to duty at the US Army Armor Center, Fort Knox, Kentucky. The average age was 20.4 years with a range of 17 to 25 years.

The $S$, apparatus, and experimenter (E) were located in a 6 by $8-\mathrm{ft}$ sound-proofed experimental booth. Illumination was furnished by a single $60-$ w overhead incandescent bulb. The instructions, read by the $\mathrm{E}$, were standard paired associate learning instructions with the exception that prior to the experimental session the learning materials were shown and pronounced to the $S$. In addition, the third randomization of the pairs was shown and read to the $S$ at the onset of all stages.

Lists of the first two stages were practiced to a criterion of two successive errorless trials. However, if the $\mathrm{S}$ did not learn one of the first two stages in 40 trials he was eliminated. All Ss received 5 trials with the test list.

\section{Results}

The mean number of correct test list anticipations for both experimental groups and their controls is 
Table 2. Mean Number of Correct Anticipations on Test Lists

\begin{tabular}{|l|c|c|c|}
\hline \multicolumn{1}{|c|}{ Group } & $\begin{array}{c}\text { Length of } \\
\text { Anticipation Interval }\end{array}$ & Mean & S.D. \\
\hline $\begin{array}{l}\text { Mediation } \\
\text { Experimental } \\
\text { (A-B, B-C, C-A) }\end{array}$ & L (4 Seconds) & 14.37 & 4.28 \\
\cline { 2 - 4 } & $\mathrm{S}$ (2 Seconds) & 10.31 & 4.84 \\
\hline $\begin{array}{l}\text { Non-Mediation } \\
\text { Control } \\
\text { (A-B, D-C, C-A) }\end{array}$ & L (4 Seconds) & 10.00 & 3.16 \\
\cline { 2 - 4 } & $\mathrm{S} \mathrm{(2} \mathrm{Seconds)}$ & 6.13 & 2.47 \\
\hline
\end{tabular}

presented in Table 2. The overall analysis of variance is significant at the .01 level $(\mathrm{F}=7.68 ; \mathrm{df}=3 / 44)$.

Duncan's (1957) multiple range test was used to evaluate the differences between treatment means. The results of this analysis are presented in Table 3. The mean difference between M-L and NM-S is significant at the .01 level. All other groups differ significantly at the .05 level with the exception of the mean difference between NM-L and NM-S. The significant differences between M-S and NM-S and M-L and NM-L indicate the occurrence of mediation. In addition, the significant difference between $\mathrm{M}-\mathrm{S}$ and $\mathrm{M}-\mathrm{L}$ indicates the importance of temporal factors in facilitating mediation.

\section{Discussion}

The results indicated a significant reverse mediation effect, which clearly supports the findings of several investigators (e.g., Horton \& Kjeldergaard, 1961; McCormack, 1961; and Jenkins, 1963). Essentially the $\mathrm{C}-\mathrm{A}$ pairs, which have in common an association with a B-word, were learned faster during the test stage than the C-A pairs with no such connection. This result may be interpreted as indicating that the second list associations are being utilized by the $\mathrm{S}$ to mediate test list learning.
Table 3. Application of Duncan Range Analysis to the Mean Number of Correct Anticipations on the Test Stage

\begin{tabular}{|c|c|c|c|c|c|}
\hline Group & & NM-S & NM-L & $M-S$ & $M-L$ \\
\hline & Mean & 6.13 & 10.00 & 10.31 & 14.37 \\
\hline $\mathrm{NM}-\mathrm{S}$ & 6.13 & 0 & 3.87 & $4.18^{*}$ & $8.24 * *$ \\
\hline NM-L & 10.00 & & 0 & .31 & $4.37 *$ \\
\hline$M-S$ & 10.31 & & & 0 & $4.06^{*}$ \\
\hline$M-L$ & 14.37 & & & & 0 \\
\hline
\end{tabular}

In addition, the present study supports the importance of temporal factors in facilitating reverse mediation. The fact that the learning of the testlist was facilitated with a longer test list anticipation interval suggests that the additional time allows $\mathrm{S}$ to decode the established habit chain $\mathrm{A} \longrightarrow \mathrm{B} \longrightarrow \mathrm{C}$ which is formed during the learning of stages 1 and 2 .

\section{References}

Ammons, R. B., \& Ammonds, C. H. The Quick Test. Missoula, Mont.: Psychological Test Specialists, 1962.

Duncan, D. B. Multiple range tests for correlated and heterosecdastic means. Biometrics, 1957, 13, 164-176.

Horton, D. L., \& Kjeldergaard, P. M. An experimental analysis of associative factors in mediated generalizations. Psychol. Monogr., 1961, 75, No. 11.

Jenkins, J. J. Mediated association: paradigms and situations. In C. N. Cofer, (Ed.), Problems and processes in verbal behavior and learning. New York: McGraw-Hill, 1963.

McCormack, P. D. Backward mediated positive transfer in a pairedassociate task. J. exp. Psychol., 1961, 61, 138-141.

Schulz, R. W., \& Lovelace, E. A. Mediation in verbal paired-associate learning: the role of temporal factors. Psychon. Sci., 1964, $1,95-96$.

Storms, L. H. Backward association in verbally mediated learning. Unpublished Ph D thesis, University of Minnesota, 1957.

Thorndike, E. L., \& Lorge, I. The teacher's word book of 30,000 words. New York: Teachers College, Columbia University, Bureau of Publications, 1944. 